Research Article

\title{
A Prediction Model for Concrete Cracks due to Chloride-Induced Corrosion
}

\author{
Jiao Wang, ${ }^{1}$ Ling Li $\mathbb{D}^{1}{ }^{1}$ X. G. Zhang, ${ }^{2}$ and Yangang Zhao ${ }^{3}$ \\ ${ }^{1}$ Department of Architecture and Civil Engineering, Guangzhou University, Guangzhou 510006, China \\ ${ }^{2}$ College of Civil and Transportation Engineering, Shenzhen University, Shenzhen 518060, China \\ ${ }^{3}$ Kanagawa University, Yokohama 250-0134, Japan
}

Correspondence should be addressed to Ling Li; 117890808@163.com

Received 4 September 2019; Revised 7 January 2020; Accepted 16 January 2020; Published 14 February 2020

Academic Editor: Lingxue Kong

Copyright (@) 2020 Jiao Wang et al. This is an open access article distributed under the Creative Commons Attribution License, which permits unrestricted use, distribution, and reproduction in any medium, provided the original work is properly cited.

The nonhomogeneity of concrete leads to randomness in the development and extension of cracks. Scholars have proposed different models to analyze the development of cracks. Different from existing works on crack development, in this paper, we establish a crack spacing model on the basis of the mechanical equilibrium relation of differential elements. We also establish a mechanical equilibrium model considering that the shrinkage of concrete is constrained by the bonding force of reinforced concrete. Then, on the basis of the equilibrium condition, we propose an analytical model of spacing between the first crack and the second crack at the interface of steel and concrete due to corrosion expansion. This calculation model has only three variables: tensile strength, effective constraint length of the reinforcement, and bond force. In addition, the parameters are clearly defined. We verified the development of cracks at the interface between steel bar and concrete under chloride corrosion at different locations in a steel bar by comparing it with existing simulations and experimental results. The analytical model proposed in this paper has an accuracy of $92 \%$, indicating that our expression for crack spacing can effectively predict the location of cracks.

\section{Introduction}

Because of chloride-induced corrosion, the volume of corrosion products of steel bars is 2-6 times that of steel bar usage [1]. The excessive internal pressure of concrete leads to cracking of concrete until structural damage occurs, which causes heavy economic losses $[2,3]$. Therefore, it is important to study concrete cover cracking due to steel corrosion.

The analysis of concrete cracks is generally divided into test detection and model analysis. In concrete structures, damage is identified by the appearance of cracks on the surface. Monitoring the level of tensile stress in the material provides an indication of microcrack localization, which leads to the formation of cracks in the medium. Kocherla and Subramaniam [4] proposed using PZT patches to measure stress waves for monitoring stress damage of concrete structures. The localization of microcracks that lead to cracks can be detected by measuring the attenuation factor of stress waves before visual detection of the surface cracks. Chang et al. [5] illustrated the use of the time-frequency analysis with Morlet wavelet transform to discriminate crack response from the rebar response and showed that time-frequency analysis can be used to identify/ verify cracks. Shi et al. [6] introduced a new electrical resistivity tomography method on the basis of the self-sensing property for detecting crack development. Fan et al. [7, 8] proposed smart reinforced concrete (RC) instrumented with a distributed fiber optic sensor for in situ monitoring, thereby offering an innovative method for quantifying mass of steel bar in steel fiber RC. If the system can successfully identify the development of artificially introduced cracks, it can also identify the growth of the actual cracks. Some scholars analyzed the development of concrete cracks on the basis of model simulation. Wang et al. [9] proposed a path probability model for predicting the stochastic corrosioncrack development of RC structures with time. They estimated the time-dependent probability distribution of steel 
corrosion ratio, crack width of concrete due to corrosion, and percentage of corroded steel samples of elements on a series of random paths of corrosion-crack process simulated by a computer program. Tran et al. [10] proposed a threedimensional rigid body spring method, combined with a three-phase material corrosion expansion model that can simulate crack propagation due to rebar corrosion. On the basis of the brittle fracture model of concrete, Wu et al. [11] proved that the position of crack initiation is perpendicular to the loading direction of the maximum displacement. Cracks are generated initially at the location closest to the interfacial layer and then through the fragile interface layer to bypass the aggregate, extending to the edge of the concrete cover, and finally through the concrete cover. Wang et al. [12] equally established a finite element model using cohesive elements. Their test results show that stirrups significantly change the crack patterns induced by inner steel corrosion. The corrosion-induced concrete crack pattern changes from the individual cracking mode to the delamination mode as the thickness of the concrete cover increases or as the rebar spacing reduces.

Currently, the research into concrete crack spacing focuses mostly on cracks of the RC beam section. The calculation methods for crack spacing of the RC beam section are mature, including the bond slip method, the no sliding method, and analysis by synthesis. In addition, there is a widely used unified specification for crack spacing on the surface of RC beams in China based on the first three methods $[13,14]$.

1.1. Bond Slip Method. The first method proposed in the tensile test for RC is the bond slip method [15]. Based on theoretical analysis, the proposed minimum value for adjacent crack spacing is $l_{\min }$, whereas the maximum value is $2 l_{\min }$. Since the actual crack spacing for the specimen has a large dispersion, the mean spacing is about $1.5 l_{\min }$. Test results were used to modify the formula for calculating mean crack spacing to the following:

$$
l_{m}=\left(k_{1}+k_{2} \frac{d}{\mu}\right) v,
$$

where $l_{m}$ is the mean crack spacing in $\mathrm{mm}$; $d$ is the steel bar diameter in $\mathrm{mm} ; \mu$ is the section reinforcement ratio; $\mu=$ $\left(A_{s} / A_{c}\right)$ in which $A_{s}$ represents the area of reinforcement and $A_{c}$ is the area of the concrete; $k_{1}$ and $k_{2}$ are parameter values obtained by regression analysis of test data in which $k_{1}=70 \mathrm{~mm}$ and $k_{2}=1.6[16]$; and $v$ reflects the surface shape coefficient of the steel bars, which has a significant influence on the bonding force between the steel bars and concrete. It is set to 1.0 for smooth round steel bars and 0.7 for deformed steel bars.

1.2. No Sliding Method. The spacing and width of tensile cracks derived by the bond slip method depend mainly on $d / \mu$ and the bond force of the RC; hence, the shape of the steel bars has a significant influence on the bonding force between the steel bars and concrete. However, the bond slip method assumes that the crack widths near the reinforcement and on the surface of the component are equal, which is inconsistent with actual results. As a result, the no sliding method was proposed; it considers that the ratio of section reinforcement and the diameter of reinforcement have little influence on the spacing of cracks. It is assumed that the relative slip of the crack section at the $\mathrm{RC}$ interface is negligible; hence, the crack width is zero, and the expression for the mean crack spacing is established as follows [17]:

$$
l_{m}=2 t \text {, }
$$

where $t$ is the distance from the location of the crack on the surface of the member to the center of the nearest steel reinforcement.

1.3. Analysis by Synthesis. By combining the bond slip method and the nonslip method, the important role of distance between the surface of the member and the reinforcement to the width of the crack is taken into account, thereby correcting the hypothesis that the relative slip and crack width on the interface of the reinforcement are zero. Considering the influence of bond slip [18], the general formula for calculating the mean crack spacing is as follows:

$$
l_{m}=k_{1} c+k_{2} \frac{d}{\mu}
$$

where $k_{1}$ and $k_{2}$ are parameter values obtained by regression analysis of the test data, determined according to the respective test data [19], and $c$ is the thickness of concrete cover.

1.4. Chinese Code for the Design of Fracture Spacing. For tensile and flexural concrete members, the crack spacing under service load is calculated by referring to existing test results and analysis from different countries. Though the main influencing factors are the same, the forms of the calculation formulas are different, resulting in different results. In the Chinese code for design of concrete structures [20], the following formula is used to calculate crack spacing in the stable stage after cracks appear in components under stress [21]:

$$
l_{m}=c_{f}\left(1.9 c+0.08 \frac{d_{\mathrm{eq}}}{\rho_{\mathrm{te}}}\right) \text {, }
$$

where $c_{f}$ depends on the coefficient of the internal force state of the member; $d_{\mathrm{eq}}$ is the equivalent diameter of tension reinforcement; $\rho_{\text {te }}$ is the reinforcement ratio, $A_{s} / A_{\text {te }}$; if $\rho_{t e}<0.01$, take $\rho_{t e}=0.01$; and $A_{\text {te }}$ is the effective section area of concrete under tension.

The above works have the following shortcomings: (1) existing research studies on development of concrete cracks are mostly based on a large number of experimental results or model simulation to obtain a general development path for cracks; (2) most of them studied crack spacing on the surface of concrete beams. Similarly, existing research methods for concrete cracks have shortcomings in predicting the development of concrete cross-sectional cracks. Since crack initiation in concrete covers due to corrosion is a critical point in evaluating the service life of corroded RC 
structures, it is vital to be able to predict the location of crack initiation with high accuracy. Moreover, few studies have been conducted on the spacing between the first and second cracks in concrete corrosion cracking based on mechanics. Several studies have been conducted on the location of the first crack, with similar conclusions. The key point of this paper is to propose an expression for average crack spacing in concrete cross sections and to use it to predict the germination position of the second crack.

\section{Prediction Model for Chloride-Induced Concrete Cracks}

2.1. Stress State of Corrosion and Cracking of RC. The tensile strength of concrete varies from section to section because of the nonuniformity of concrete. The first crack appears in the weakest section as the load increases. The tensile stress of concrete is zero at the crack section, where it is transferred to the reinforcement. The stress and strain of the steel bar increase rapidly during cracking. When the stress on the concrete is released after a long stretch, the concrete will instantly shrink back; thus, the cracks will have a certain width when they appear.

The concrete shrinks after cracking, and it is restrained by the bond force of the RC, as shown in Figure 1. Tensile stress will be reestablished at a distance from the crack section. As the load increases, the tensile stress on the concrete increases at a certain length from the crack section, leading to the appearance of the second crack.

2.2. Mean Fracture Spacing. Reinforcement plays a role only within the effective tensile area. When cracks occur, only concrete within a limited range around the reinforcement is restrained by the reinforcement, whereas those far from the reinforcement are less affected by the constraint of the reinforcement. As shown in Figure 2, reinforcement with mean crack spacing, $l_{m}$, and the tensile concrete within the effective range are taken as the differential field. We analyze the crack spacing of concrete cross sections on the basis of the analysis method of 1.1-1.4 about the surface crack spacing of concrete beams.

Figure 3 shows a differential field enclosed by two cylinders separated by $\mathrm{d} \rho$. Two radial planes with an angle of $\mathrm{d} \varphi$ is cut out from the long cylinder. This differential field can be used to analyze the stress between the first crack and the second crack in chloride-induced corrosion cracking within the effective tensile range of the concrete.

Taking the thickness of the differential field as unity, $\mathrm{d} \varphi$ is small; hence, $\sin (\mathrm{d} \varphi / 2)$ can be approximated as $\mathrm{d} \varphi / 2$ and $\cos (\mathrm{d} \varphi / 2)$ can be approximated as 1.0. Based on elasticity, the equilibrium conditions can be obtained as follows:

$$
\begin{aligned}
\tau_{\rho \varphi} \rho \mathrm{d} \varphi \cos \frac{\mathrm{d} \varphi}{2} & =\sigma_{\varphi} \mathrm{d} \rho, \\
\tau_{\rho \varphi} \rho \mathrm{d} \varphi & =\sigma_{\varphi} \mathrm{d} \rho .
\end{aligned}
$$

When the differential field is analyzed as concrete, $\tau_{\rho \varphi}$ can be regarded as $\tau_{m}$, where $\tau_{m}$ represents the bond force of

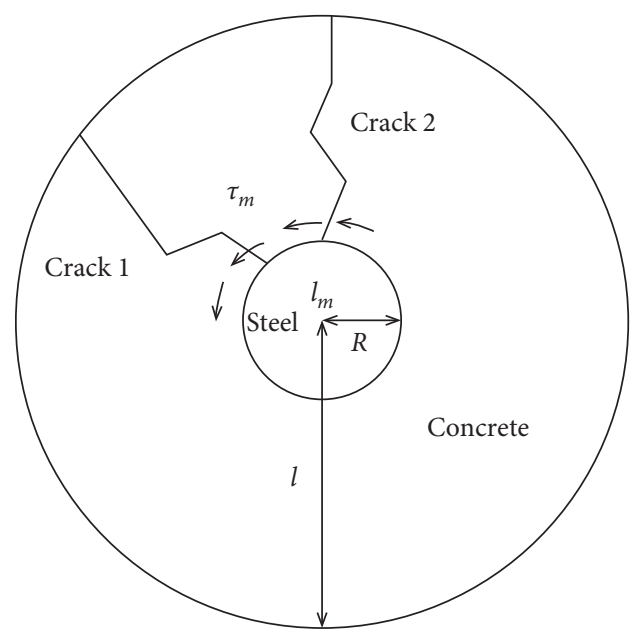

FIgURE 1: Schematic diagram of concrete crack development. $\tau_{m}$ - the bond force of RC, $\mathrm{N}$; $R$-radius of reinforcing bar, mm; $l$-radius of RC cylinder, $\mathrm{mm}$.

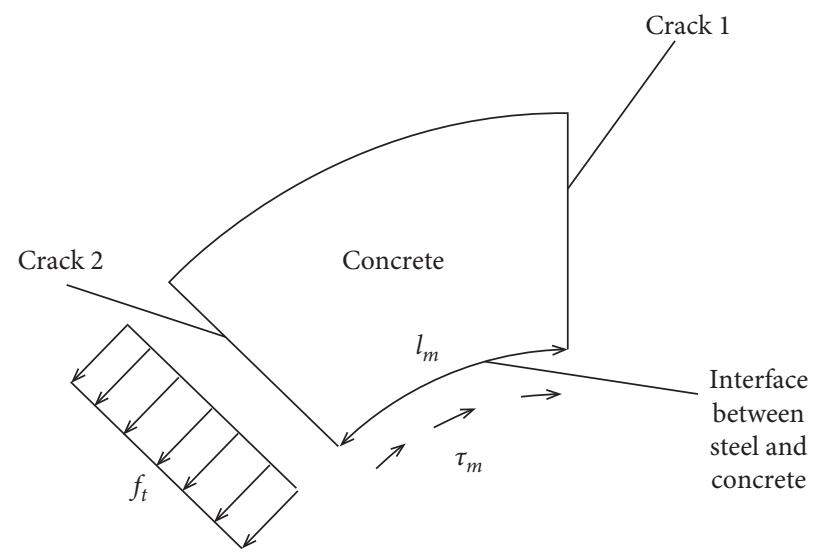

Figure 2: The concrete micromechanics are stressed within the effective tensile range between two cracks. $f_{t}$ - the tensile strength of concrete, $\mathrm{N} / \mathrm{mm}^{2}$.

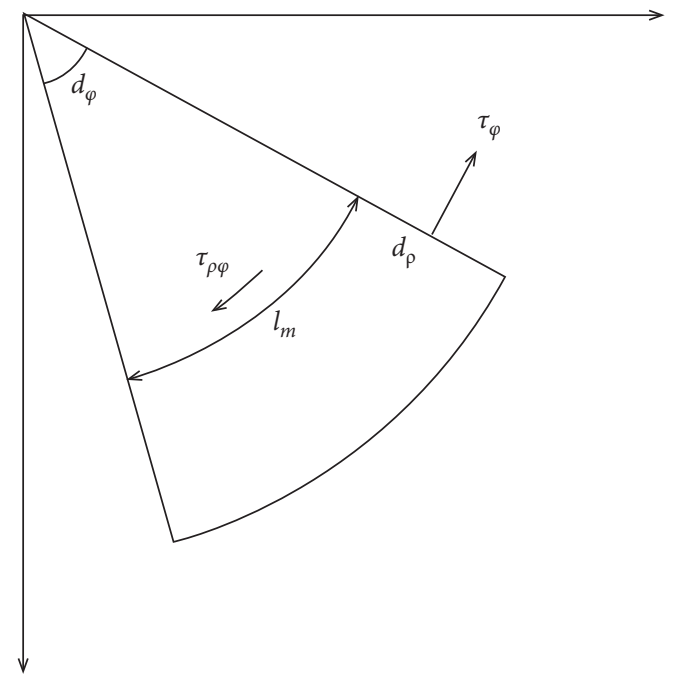

FIGURE 3: Elastic mechanics analysis of concrete differentials. $\mathrm{d} \rho$-distance between two cylinders of a thick-walled cylinder; $\mathrm{d} \varphi$-angle cut between two radial planes; $\sigma_{\varphi}$-circular normal stress; $\tau_{\rho \varphi}$-shear stress of the cylinder. 
RC; $d \rho$ can be thought of as the effective tensile length of the concrete, which can be obtained from its effective tensile area. The circumferential tensile stress reaches the tensile strength, $f_{t}$, of the concrete when concrete cracks; hence, $\sigma_{\varphi}$ can be regarded as the tensile strength, $f_{t}$, of the concrete. The ultimate cracking stress state can be expressed as follows:

$$
\sigma_{\varphi}=f_{t} .
$$

Substituting equation (6) into (5), the mean crack spacing, $l_{m}$, can be expressed as follows:

$$
l_{m}=\frac{f_{t} R_{c}}{\tau_{m}},
$$

where $R_{c}$ is the effective tensile length of concrete in $\mathrm{mm}$.

\section{Verification Based on Existing Test and Simulation Results}

3.1. Calculation Example. Combined with the corrosion experiment of reinforced concrete proposed by the existing scholars [22], the steel bar has a diameter of $18 \mathrm{~mm}$, whereas the concrete cover is 4.5 times the diameter of the steel bar, as shown in Figure 4. The properties of concrete materials are shown in Table 1: $f_{c}=30.1 \mathrm{~N} / \mathrm{mm}^{2}$ and $f_{t}=2.54 \mathrm{~N} / \mathrm{mm}^{2}$.

Industrial computerized tomography (ICT) nondestructive testing system was used to scan the specimens and observe the development of internal cracks in concrete. Figure 5(a) shows that cracking in the surface of the specimen has cracked, whereas Figure 5(b) clearly shows that three cracks occurred. Figure 6 shows the ICT scan results for cracks in concrete under different rust rates. It shows the crack development process for concrete during corrosion, from no cracks to the gradual development of three cracks. This paper will adopt these results as an example to verify the feasibility of the proposed fracture spacing prediction model.

To calculate the distance between crack 1 and crack 2, it is necessary to obtain the bonding force of the RC. The bonding force can be determined by the following equation [23]:

$$
\tau_{m}=0.6 f_{c}^{2 / 3}
$$

where $f_{c}$ is the compressive strength of concrete, $\mathrm{N} / \mathrm{mm}^{2}$. The thickness of the concrete cover is 4.5 times the diameter of the steel bar, so it can be expressed as follows:

$$
c=4.5 d=81 \mathrm{~mm} \text {. }
$$

According to the method for calculating the effective tensile area of concrete beam under axial compression, the effective tensile length of concrete can be expressed as follows [20, 24-26]:

$$
R_{c}=c=81 \mathrm{~mm} \text {. }
$$

Substituting equations (8) and (10) into (7), the expression for crack spacing of concrete can be obtained as follows:

$$
l_{m}=\frac{f_{t} R_{c}}{\tau_{m}}=35.47 \mathrm{~mm} .
$$

3.2. Verification of Different Data. We randomly selected eight simulation and test results from existing works, as shown in Figures 7(a)-7(i) [33]. We found from these results that the position of the steel reinforcement affects the development of cracks. Corrosion cracks of nonmiddle steel reinforcement with different concrete cover are divided into cracks. First, cracks appear on both sides of the reinforcement, forming an internal horizontal crack [34] and then cracks again in the easily damaged part of concrete. The development law of these cracks is consistent with the test results [24]. When the steel bar is in the middle of the concrete, the distribution of the three cracks is approximately $120^{\circ}$, which is consistent with the results in [35]. Compared with nonmiddle steel reinforcement, the crack spacing of steel bars located in the middle of concrete is more evenly distributed [33].

It is difficult to measure the spacing between the starting points of cracks because of the small deformations caused by reinforcement corrosion. Therefore, angle verification is adopted to verify the crack development law. The angle can be expressed as follows based on geometric relationships:

$$
\theta=\frac{360 l_{m}}{2 \pi R}
$$

Substituting equation (11) into (12), the angle between the two cracks can be expressed as follows:

$$
\theta=\frac{360 l_{m}}{2 \pi R}=226^{\circ}
$$

Equation (13) shows that the angle is obtuse. To facilitate calculation and comparison, the angle between two cracks can be expressed as follows:

$$
\theta^{\prime}=360-\theta=134^{\circ}
$$

Table 2 shows that the diameter of the steel reinforcement and thickness of the concrete cover influence the development of cross-sectional cracks. It is worth noting from the data in groups $\mathrm{d}$ and $\mathrm{f}$ that though the steel bars have different diameters, the crack spacing is equal in both cases and the crack angle is significantly different. Therefore, we assumed that the diameter of the steel bar does not affect the crack spacing. However, the larger the diameter of the steel bars, the smaller the crack angle. The data in groups e and $g$ show that other factors are uniform except the thickness of concrete cover. When the diameter of the reinforcing bar is the same, the bigger the concrete cover, $c$, the greater the spacing and angle between the first and second cracks. Thus, it can be hypothesized that an increase in concrete cover leads to an increase in crack spacing.

To prove the applicability of the proposed prediction model for concrete crack spacing, we compared the data from existing research and evaluated the error between the calculated and actual results in concrete crack spacing. The result of the comparison led us to propose that prediction 


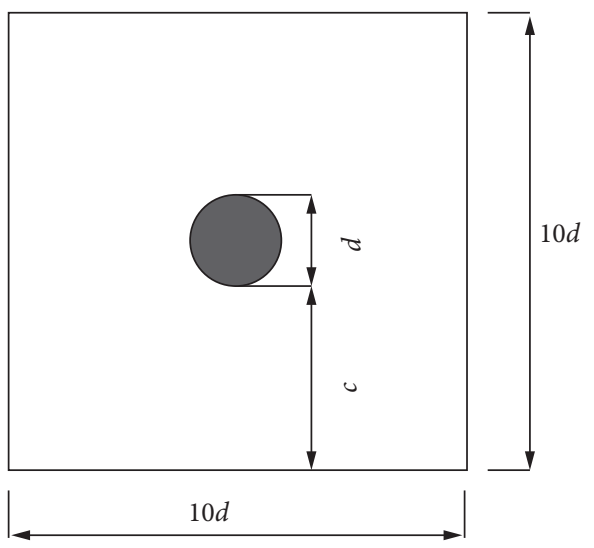

FIGURE 4: Elastomechanical analysis of concrete differentials.

model has an accuracy of up to $92 \%$. Some large error results were observed, which can be attributed to the following reasons. First, there is a deviation in determining the center of the reinforcing bar because of microdeformations due to corrosion of the bar. In addition, the mode of crack propagation is complex. Once the crack propagates, it will have a certain width [36]. It is difficult to determine the crack propagation point because the direction of the crack propagation angle is uncertain.

\section{Factors That Influence Concrete Spacing}

4.1. Concrete Cover and Diameter of the Reinforcement. To investigate the effect of concrete cover and the diameter of steel bar on the concrete crack spacing in RC, we calculated crack spacing using concrete cover within a range of $30-50 \mathrm{~mm}$ and steel bar diameters of 16 and $20 \mathrm{~mm}$. Figure 8(a) shows that concrete with different steel bar diameters have the same crack spacing. Moreover, an increase in concrete cover leads to an increase in crack spacing. This further verifies the preliminary assumption of the thickness of concrete cover and crack spacing in Section 3.2. We compared the calculation results with the measurement results, using a steel bar with a diameter of $16 \mathrm{~mm}$ as an example. The result shows that the concrete crack spacing of $\mathrm{RC}$ interface advanced from about 7.76 to $12.93 \mathrm{~mm}$, as the concrete cover changes from 30 to $50 \mathrm{~mm}$ and the error decreases with increasing concrete cover. This is because the larger the concrete cover is, the smaller the crack width is and the closer the measurement results are to the actual results. When the thickness of concrete cover is $30 \mathrm{~mm}$, the error between the measured and calculated results is $11.72 \%$. The large error of a small amount of data is due to the crack width when concrete cracks, which may lead to errors in the measured results. In addition, Figure 8(a) also shows that the proposed prediction model for crack spacing proposed is consistent with actual results. It is worth noting that the error in most of the results is very small, which satisfies the accuracy of the concrete crack spacing prediction model proposed in this paper.

Though the diameter of the steel bar does not affect the crack spacing of the concrete, an increase in the diameter of the steel bar results in a decrease in the crack angle, as shown in Figure 8 (b). Therefore, the larger the diameter of the reinforcing bar is, the higher the number of cracks that may occur.

4.2. Effective Tensile Length, $R_{c}$. We quantitatively analyzed the influence of different parameters according to the concrete crack prediction model proposed above. Based on the strength of C30 concrete, the following general quantitative values were used: $f_{t}=1.5 \mathrm{~N} / \mathrm{mm}^{2}, R_{c}=30 \mathrm{~mm}$, and $\tau_{m}=5.8 \mathrm{~N}$. To analyze the relationship between $\tau_{m}$ and $l_{m}$, we calculated the concrete crack spacing with the following values: $f_{t}=1.5 \mathrm{~N} / \mathrm{mm}^{2}, R_{c}=20-40 \mathrm{~mm}$, and $\tau_{m}=4.0-9.0 \mathrm{~N}$.

The calculation results shown in Figure 9 indicate that the crack spacing decreases as the bonding force of RC increases if the parameters in the models are the same. In addition, the crack spacing of concrete with an effective tensile length of $40 \mathrm{~mm}$ is obviously larger than that of the concrete with an effective tensile length of $20 \mathrm{~mm}$. With the same diameter of steel bar, an increase in the concrete cover increases the effective tensile length of the concrete. The methods for determining the effective tensile length of concrete are as follows:

(1) When the reinforcement is in the middle of the concrete, the effective tensile length of concrete is evaluated according to the method for calculating the effective tensile area of the concrete beam under axial compression. In detail, when the thickness of cover is less than seven times the diameter of the reinforcement, the effective tensile area of concrete is the actual concrete area [24-26].

(2) When the steel reinforcement is not in the middle of the concrete, $R_{c}$ represents the effective tensile length of concrete cover at the thin side.

As the bonding force increases, the crack spacing of the concrete decreases gradually to a constant value. It can be assumed that a bonding force that is much larger than the tensile strength of the concrete has little effect on crack spacing; hence, the crack spacing tends to be stable under such conditions. When the spacing of concrete cracks is zero, the concrete does not suffer from corrosion expansion and cracking. Different curve slopes show that the larger the effective tensile length of the concrete, the more obvious the reduction in the rate of crack spacing.

4.3. The Tensile Strength, $f_{t}$, of the Concrete. To analyze the relationship between $f_{t}$ and $l_{m}$, we assumed that the concrete has a tensile strength of $2.7 \mathrm{~N} / \mathrm{mm}^{2}$ and a cohesive force of $5.8 \mathrm{~N}$ for the model calculation. Figure 10 shows that the effective tensile length of the concrete increases from 20 to $40 \mathrm{~mm}$, causing the crack spacing to advance from 5.17 to $10.34 \mathrm{~mm}$. We verified that increasing the tensile length of concrete increases the crack spacing of the concrete. The tensile strength of the concrete increases from 1.5 to $2.7 \mathrm{~N} /$ $\mathrm{mm}^{2}$ for a concrete cover of $40 \mathrm{~mm}$, which increases the concrete crack spacing from 10.34 to $18.62 \mathrm{~mm}$. This phenomenon shows that an increase in the tensile strength of 
TABLE 1: Characteristic value of cubic concrete compressive strength.

\begin{tabular}{|c|c|c|c|c|}
\hline Specimen type & Ultimate bearing capacity $(\mathrm{kN})$ & Compressive strength $\left(\mathrm{N} / \mathrm{mm}^{2}\right)$ & Mean value $\left(\mathrm{N} / \mathrm{mm}^{2}\right)$ & Tensile strength $\left(\mathrm{N} / \mathrm{mm}^{2}\right)$ \\
\hline \multirow{3}{*}{$150 \times 150 \times 150 \mathrm{~mm}^{3}$} & 709.0 & 31.5 & \multirow{3}{*}{30.1} & \multirow{3}{*}{2.54} \\
\hline & 679.9 & 30.2 & & \\
\hline & 640.9 & 28.5 & & \\
\hline
\end{tabular}

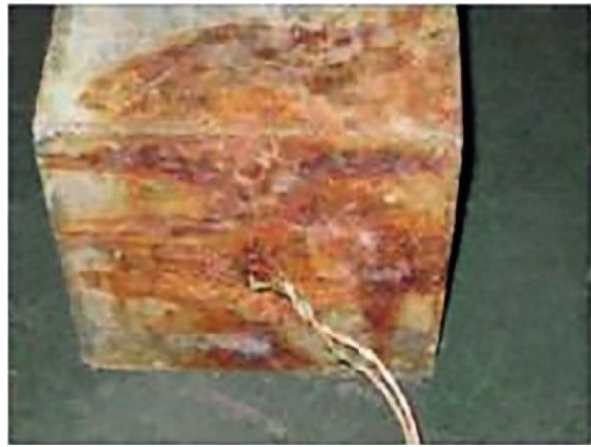

(a)

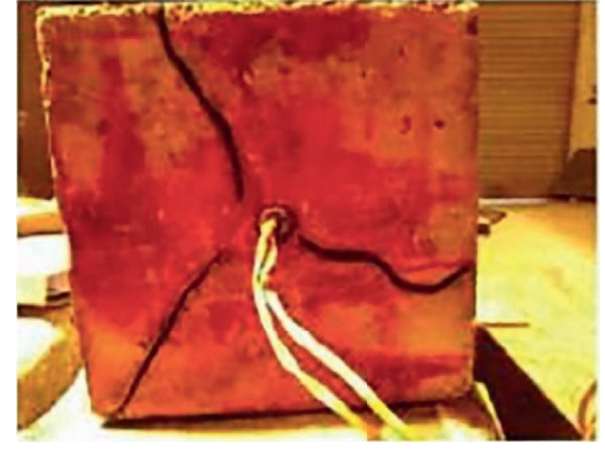

(b)

FIGURE 5: Corrosion expansion cracks of specimens. (a) Corrosion rate $\eta=3.6 \%$. (b) Corrosion rate $\eta=4.5 \%$.

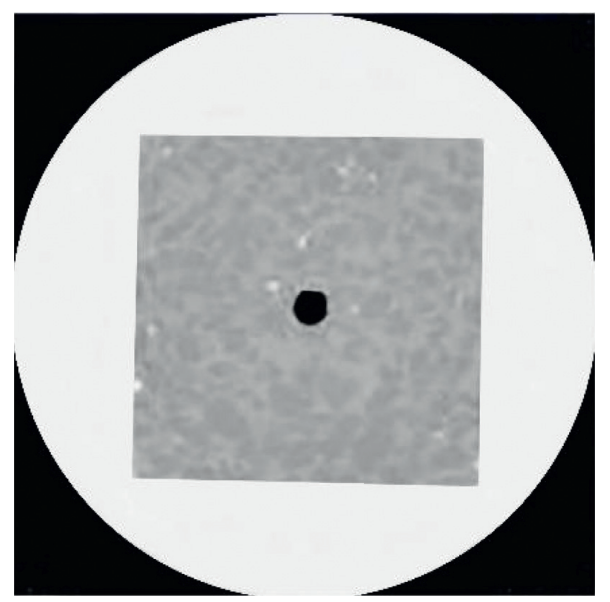

(a)

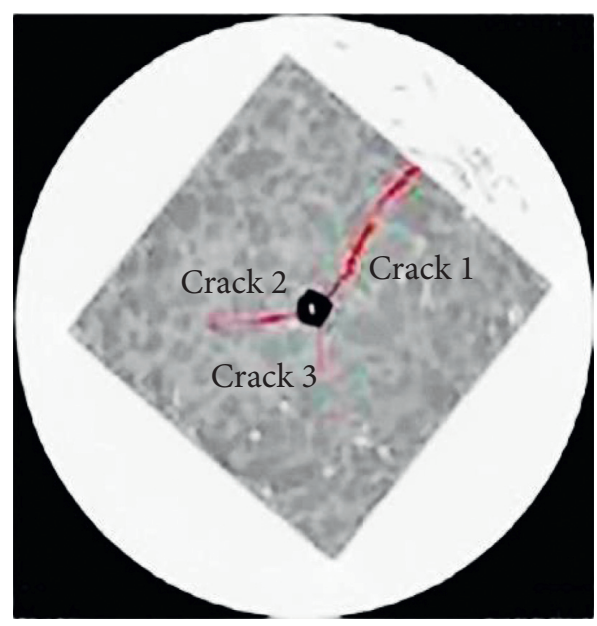

(c)

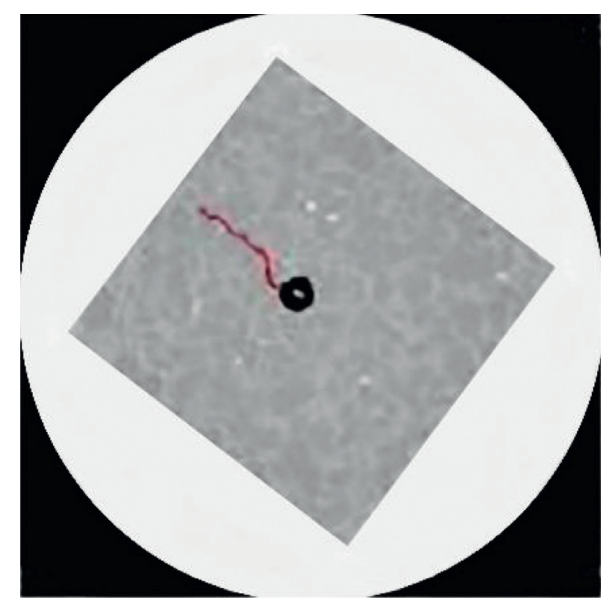

(b)

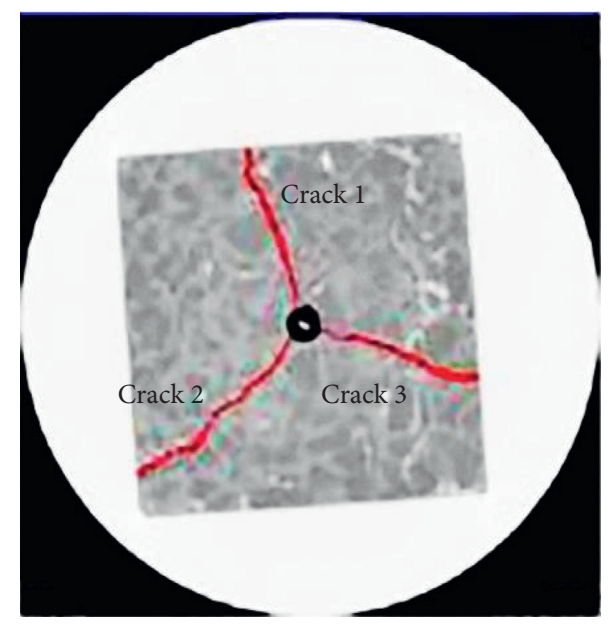

(d)

Figure 6: Specimen detecting test. (a) Corrosion rate $\eta=2.6 \%$. (b) Corrosion rate $\eta=3.2 \%$. (c) Corrosion rate $\eta=3.6 \%$. (d) Corrosion rate $\eta=4.5 \%$. 


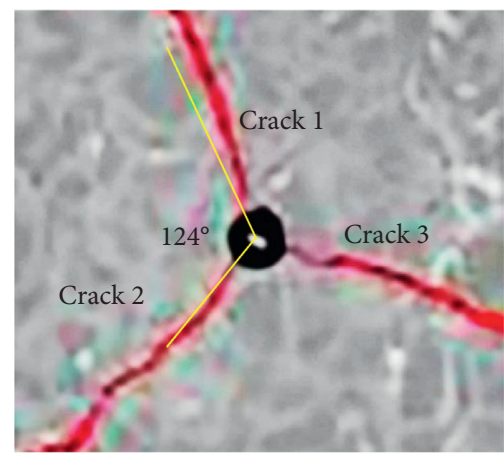

(a)

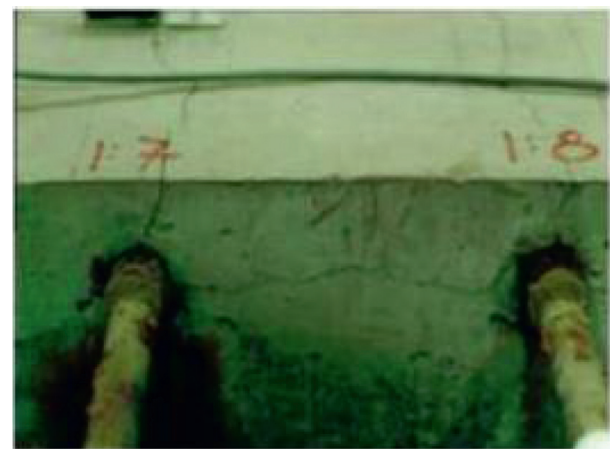

(c)

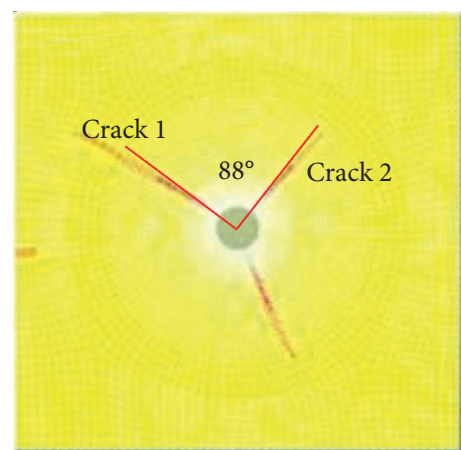

(b)

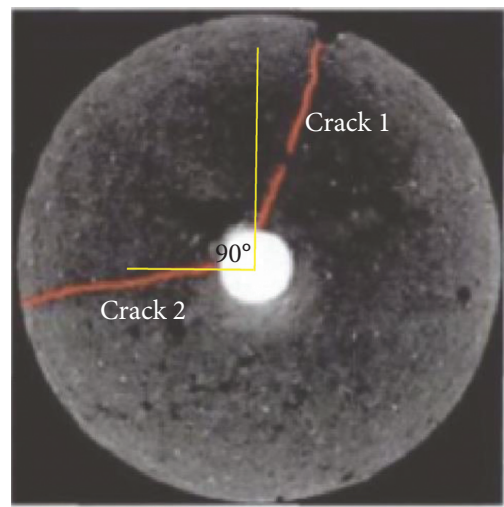

(d)

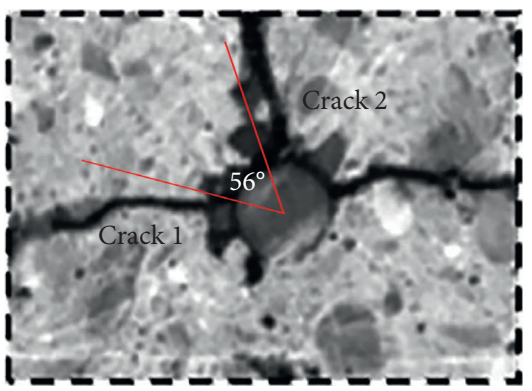

(e)

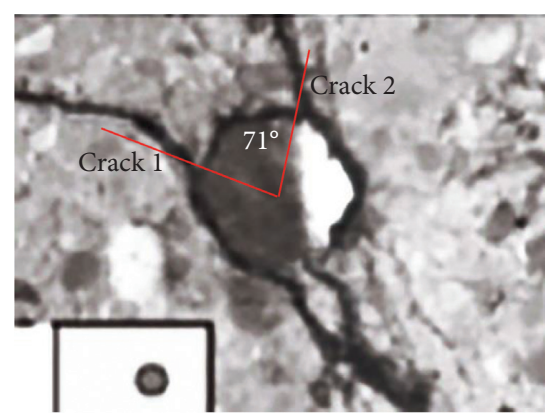

(g)

(f)

FIgURE 7: Continued. 


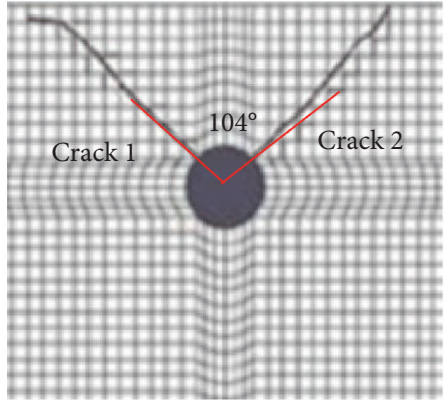

(h)
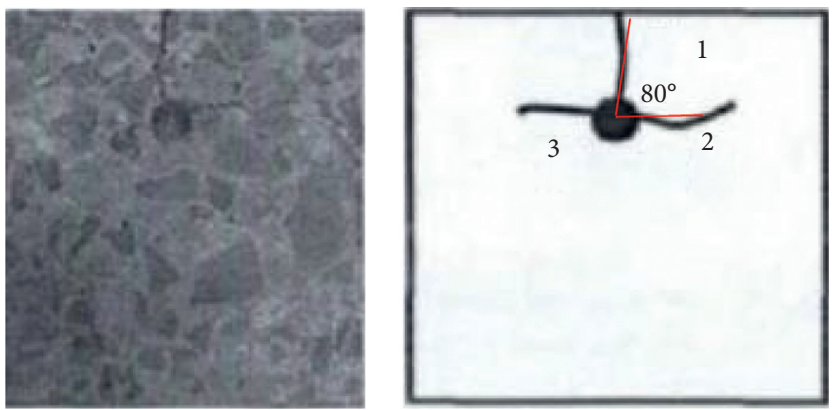

(i)

FiguRE 7: Location of corrosion cracks in reinforced concrete. (a) Scan image of the specimen of the middle reinforcement [22]. (b) Crack development paths with different thicknesses of cover [22]. (c) The crack form of plate type test [27]. (d) Simulating the development of corrosion cracks in the middle reinforcement [28]. (e) Simulation and test of steel corrosion with different covers [29]. (f) Results of cracking tests of corner reinforcement $(d=12 \mathrm{~mm} ; c=20 \mathrm{~mm})$ [30]. (g) Results of cracking tests of corner reinforcement $(d=12 \mathrm{~mm} ; c=20 \mathrm{~mm})$ [30]. (h) Finite element simulation different covers [31]. (i) Cross-section corrosion crack pattern with development with of non-central of crack reinforcement [32].

TABLE 2: Crack spacing data comparison and error.

\begin{tabular}{lccccccccc}
\hline Group & $D(\mathrm{~mm})$ & $c(\mathrm{~mm})$ & $f_{c}\left(\mathrm{~N} / \mathrm{mm}^{2}\right)$ & $f_{t}\left(\mathrm{~N} / \mathrm{mm}^{2}\right)$ & $\tau_{m}(\mathrm{~N})$ & $l_{m}(\mathrm{~mm})$ & $\theta_{c}\left({ }^{\circ}\right)$ & $\theta_{m}\left({ }^{\circ}\right)$ & $r(\%)$ \\
\hline a & 18 & 81 & 30.1 & 2.54 & 5.8 & 21.05 & 134 & 124 \\
b & 16 & 30 & 30 & 2.2 & 5.8 & 11.38 & 81.54 & 88 \\
d & 6.5 & 20 & 30 & 1.5 & 5.8 & 5.17 & 91.23 & 90 \\
e & 16 & 30 & 30 & 1.5 & 5.8 & 7.76 & 55.6 & 56 \\
f & 12 & 20 & 30 & 1.5 & 5.8 & 5.17 & 49.42 & 53 & 0.71 \\
g & 16 & 35 & 30 & 1.5 & 5.8 & 9.05 & 64.86 & 71 \\
h & 12 & 27 & 35 & 2.72 & 6.42 & 11.44 & 109.29 & 104 \\
i & 10 & 30 & 46.3 & 1.7 & 7.74 & 6.59 & 75.5 & 80 \\
\hline
\end{tabular}

$\theta_{c}-$ calculated angle in degrees; $\theta_{m}-$ measured angle in degrees; $r$-error between the measured and calculated angles; $r=\left(\left|\theta_{c}-\theta_{m}\right| / \theta_{m}\right) \%$.

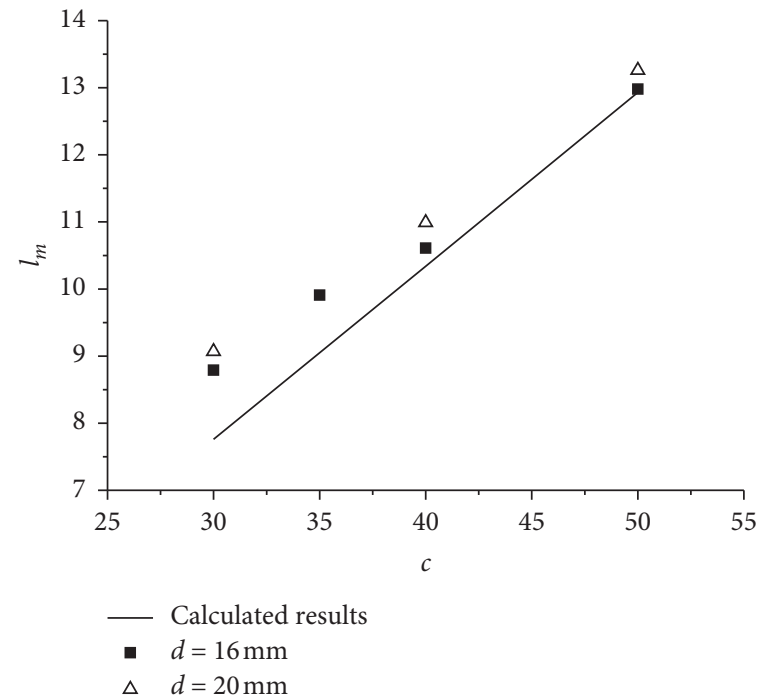

(a)

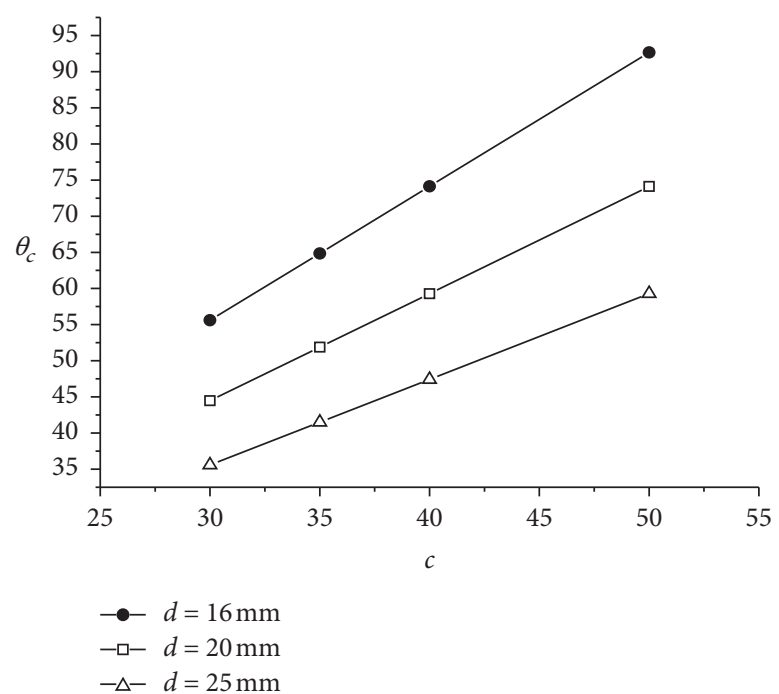

(b)

FIGURE 8: The relationship between concrete cover and the concrete crack spacing [18]. (a) Calculating and measuring crack spacing $(d=16 \mathrm{~mm}$ and $20 \mathrm{~mm}$ ). (b) Calculation results of crack spacing of concrete with different diameters of reinforcing bars.

concrete leads to a significant increase in crack spacing of the concrete. This trend becomes more obvious as the tensile strength of the concrete increases.
4.4. The Bond Force, $\tau_{m}$, between $R C$. If other factors in the model are constant, then the crack spacing of the concrete is proportional to the tensile strength of the concrete. The 


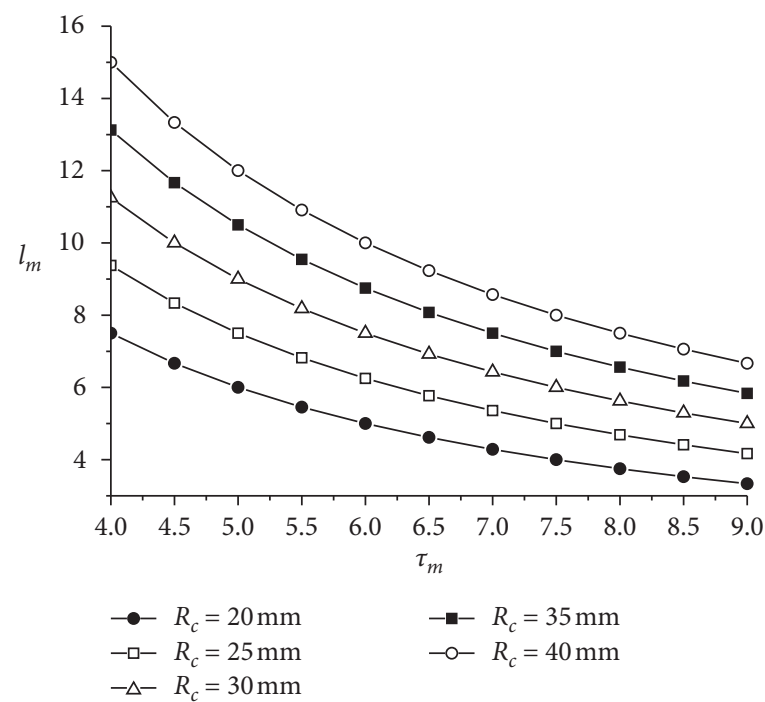

Figure 9: The relationship between $\tau_{m}$ and $l_{m}\left(f_{t}=1.5 \mathrm{~N} / \mathrm{mm}^{2}\right)$.

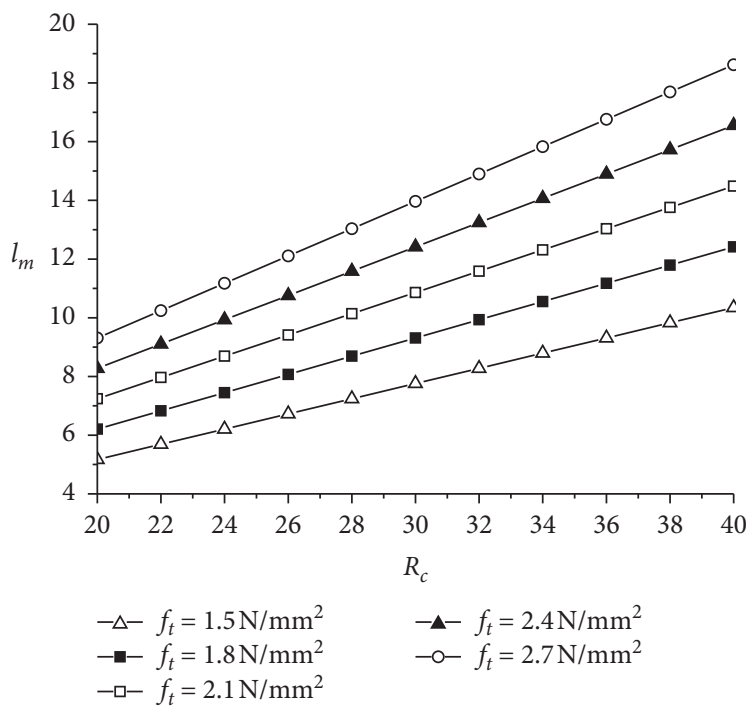

FIgURE 10: The relationship between $R_{c}$ and $l_{m}\left(\tau_{m}=5.8 \mathrm{~N}\right)$.

growth trend of crack spacing and concrete tensile strength is similar to that of crack spacing and effective tensile length of concrete. Figure 11 shows that crack spacing increases the tensile strength of the concrete increases. In addition, the increase in crack spacing is constant if all other factors remain constant. In case that factors other than the bonding force are the same, the rate of crack spacing of the concrete decreases with increasing $\tau_{m} . f_{t}$ is most sensitive to crack spacing when the effective length of the concrete is $30 \mathrm{~mm}$ and the bonding force is $4 \mathrm{~N}$. Therefore, the smaller the bonding force is, the more remarkable the crack spacing increases with the tensile strength of the concrete.

4.5. The Most Sensitive Influencing Factor of Crack Spacing in Concrete. $\tau_{m}$ is composed of chemical bonding force, friction force, mechanical bite force, and anchorage force at the end of steel bar and mainly depends on the roughness of the material itself and has nothing to do with the external environment. As a result, the error in tensile strength of the concrete and bonding force of RC is very small if the strength of the concrete has been determined in practical engineering. Table 3 shows that the increase in tensile strength of the concrete does not exceed $0.2 \mathrm{~N} / \mathrm{mm}^{2}$. The increase in concrete cover is multiplied by $5 \mathrm{~mm}$, as shown in Table 4 . Combined with existing research data and theoretical analysis, the influence of concrete tensile strength on crack spacing is more sensitive than the effective tensile length and bonding force of concrete. Therefore, it can be assumed that the tensile strength of concrete is most sensitive to the crack spacing of concrete.

We used concrete with a calculated strength of C30 as an example to determine the most sensitive influencing factor of crack spacing in concrete. The model has a tensile strength of $1.5 \mathrm{~N} / \mathrm{mm}^{2}$, bonding force of $5.8 \mathrm{~N}$, and concrete cover of 


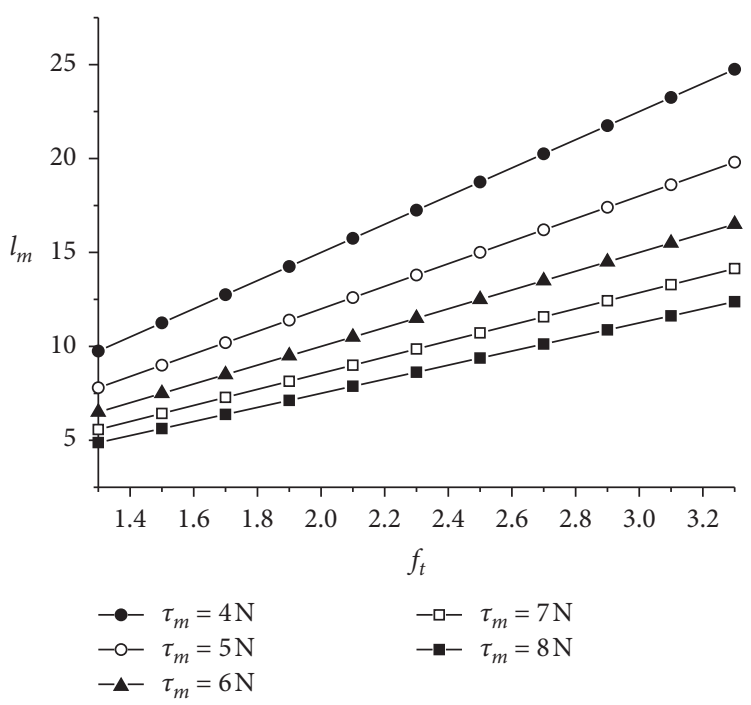

FIgURE 11: The relationship between $f_{t}$ and $l_{m}\left(R_{c}=30 \mathrm{~mm}\right)$.

TABLE 3: Design value of axial tensile strength of concrete $\left(\mathrm{N} / \mathrm{mm}^{2}\right)$.

\begin{tabular}{lllllllllllll}
\hline Strength grade of concrete & C15 & C20 & C25 & C30 & C35 & C40 & C45 & C50 & C55 & C60 & C65 & C70 \\
\hline$f_{t}$ & 0.91 & 1.10 & 1.27 & 1.43 & 1.57 & 1.71 & 1.80 & 1.89 & 1.96 & 2.04 & 2.09 & 2.14 \\
\hline
\end{tabular}

Table 4: Minimum thickness of concrete cover (mm).

\begin{tabular}{lcc}
\hline Environmental classification & Panels, walls, and shells & Beams, columns, and poles \\
\hline - & 15 & 20 \\
二 & 20 & 25 \\
三 & 25 & 35 \\
三a & 30 & 40 \\
三 & 40 & 50 \\
\hline
\end{tabular}

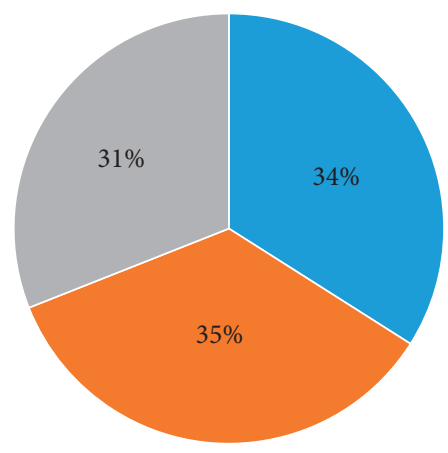

$f_{t}=1.7 \mathrm{~N} / \mathrm{mm}^{2}$

- $R_{c}=35 \mathrm{~mm}$

$\tau_{m}=5.6 \mathrm{~N}$

Figure 12: The influence of three variables $f_{t}, R_{c}$, and $\tau_{m}$ on concrete crack spacing.

$30 \mathrm{~mm}$. Figure 12 illustrates the influence of three variables, $f_{t}, R_{c}$, and $\tau_{m}$, on concrete crack spacing. The results calculated from the initial variables are taken as control group. In addition, the crack spacing of concrete is calculated with results from practice, assuming a tensile strength of $1.7 \mathrm{~N} /$ $\mathrm{mm}^{2}$, effective tensile length of $35 \mathrm{~mm}$, and bonding strength of RC of $5.6 \mathrm{~N}$. Compared with the control group, when the tensile strength of concrete is $1.7 \mathrm{~N} / \mathrm{mm}^{2}$, the influence on the crack spacing of concrete is $34 \%$, and when the concrete cover is $35 \mathrm{~mm}$, the influence on the crack spacing of concrete is $35 \%$, which is far greater than that of the bonding force of concrete. The effect of an increase of $0.2 \mathrm{~N} / \mathrm{mm}^{2}$ in concrete tensile strength on crack spacing is almost the same as that of an increase of $5 \mathrm{~mm}$ in concrete cover, which indicates that concrete tensile strength has the most sensitive influence on crack spacing.

\section{Conclusion}

(1) Through mechanical theory analysis, we established an average crack spacing model for concrete on the basis of the constraint of the RC bonding force and verified the experimental results with existing research.

(2) After the location of the first crack is known, the expression for average crack spacing proposed in this 
paper can be used to predict the location of the second crack.

(3) The theoretical model proposed in this paper is suitable for the analysis of crack spacing in concrete cross sections. It can accurately predict the average crack spacing in concrete cross sections.

(4) The crack spacing of concrete is affected by the thickness of concrete cover, its tensile strength, effective tensile length, the bonding force of $\mathrm{RC}$, and the diameter of reinforcement. We proved that the tensile strength of concrete has a significant influence on its crack spacing.

(5) To validate the proposed model, we compared our results with experimental results from the existing literature. It can be concluded that the combined analytical and numerical model developed herein can be used to accurately predict crack spacing due to chloride-induced corrosion in RC.

\section{Data Availability}

Previously reported data were used to support this study. These prior studies (and datasets) are cited at relevant places within the text as references.

\section{Conflicts of Interest}

The authors declare that they have no conflicts of interest.

\section{References}

[1] C. Lu, Y. X. Zhao, and W. L. Jin, "Prediction model of corrosion cracking time of corroded reinforced concrete cover," Journal of Building Structures, vol. 31, no. 2, pp. 85-92, 2010.

[2] L. Wang, L. Dai, H. Bian, Y. Ma, and J. Zhang, "Concrete cracking prediction under combined prestress and strand corrosion," Structure and Infrastructure Engineering, vol. 15, no. 3, pp. 285-295, 2019.

[3] L. Dai, H. Bian, L. Wang, M. Potier-Ferry, and J. Zhang, "Prestress loss diagnostics in pre-tensioned concrete structures with corrosive cracking," Journal of Structural Engineering, vol. 146, no. 3, Article ID 04020013, 2019.

[4] A. Kocherla and K. V. L. Subramaniam, "Stress and damage localization monitoring in fiber-reinforced concrete using surface-mounted PZT sensors," Measurement Science and Technology, vol. 31, no. 2, Article ID 024004, 2020.

[5] C.-C. Chang, C.-P. Yu, and Y. Lin, "Distinction between crack echoes and rebar echoes based on morlet wavelet transform of impact echo signals," NDT \& E International.vol. 108, Article ID 102169, 2019.

[6] L. Shi, Y. Lu, and R. Q. Guan, "Detection of crack development in steel fibre engineered cementitious composite using electrical resistivity tomography," Smart Materials and Structures, vol. 28, no. 12, pp. 1-17, 2019.

[7] L. Fan, Y. Bao, and G. Chen, "Feasibility of distributed fiber optic sensor for corrosion monitoring of steel bars in reinforced concrete," Sensors, vol. 18, no. 11, p. 3722, 2018.

[8] L. Fan, Y. Bao, W. Meng, and G. Chen, "In-situ monitoring of corrosion-induced expansion and mass loss of steel bar in steel fiber reinforced concrete using a distributed fiber optic sensor," Composites Part B: Engineering, vol. 165, pp. 679-689, 2019.

[9] X. Z. Wang, W. L. Jin, and Y.-D. Yan, "Path probability model of corrosion-crack assessment for existing reinforced concrete structures," Journal of Zhenjiang University: Engineering Science, vol. 44, no. 6, pp. 1191-1196, 2010.

[10] K. K. Tran, H. Nakamura, K. Kawamura, and M. Kunieda, "Analysis of crack propagation due to rebar corrosion using RBSM," Cement and Concrete Composites, vol. 33, no. 9, pp. 906-917, 2011.

[11] P. Wu, K. Du, Y. Xu, and W. Chen, "Meso-scale numerical simulation of corrosion cracking process of reinforced concrete based on brittle cracking model," Bulletin of the Chinese Ceramic Society, vol. 37, no. 8, pp. 2372-2377, 2018.

[12] K. Wang, Y. Zhao, and J. Xia, "Experimental study and numerical simulation of corrosion-induced crack patterns of concrete structures," Journal of Building Structures, vol. 40, no. 7, pp. 138-145, 2019.

[13] Z. Ren and X. Zeng, "Cracks of wide-notch concrete beams strengthened with near-surface mounted CFRP bars based on quasi-plane assumption," Journal of Building Structures, vol. 40, no. 12, pp. 88-95, 2019.

[14] C. Heng, Y. Zhao, and A. Zhu, "Experimental investigation on short-term cracking behavior of lightweight concrete beams reinforced with high-yield strength rebars," Journal of Building Structures, vol. 40, no. 5, pp. 80-88, 2019.

[15] R. Saligar, High Grade Steel in Reinforced Concrete, Preliminary Publication, 2nd Congress of IABSE, Berlin-Munich, Germany, 1936.

[16] Sichuan Institute of Architectural Science, Calculation of Crack Width of Reinforced Concrete Axial Tensile Member, Academy of Architectural Sciences, State Construction Commission, Selection of Research Reports on Reinforced and Concrete Structures, China Architecture \& Building Press, Beijing, China, 1977.

[17] A. Soltani, K. A. Harries, B. M. Shahrooz, and Shahrooz, "Crack opening behavior of concrete reinforced with high strength reinforcing steel," International Journal of Concrete Structures and Materials, vol. 7, no. 4, pp. 253-264, 2013.

[18] J. F. Borges and J. A. Lima, Formation of Cracks in Beams with Low Percentage of Reinforcement, RILEM Symposium, Stockholm, Sweden, 1957.

[19] A. W. Beeby, The Prediction and Control of Flexural Cracking in Reinforced Concrete Members, ACI SP-30, Detroit, MI, USA, 1971.

[20] China Architecture \& Building Press, National Standards of the People's Republic of China GB 50010-2010 Code for Design of Concrete Structures, China Architecture \& Building Press, Beijing, China, 2010.

[21] R. H. Evans and M. S. Marathe, "Microcracking and stressstrain curves for concrete in tension," Matériaux et Constructions, vol. 1, no. 1, pp. 61-64, 1968.

[22] J. Cheng, Preliminary Study on the Concrete Cover CorrosionInduced Cracking by the Application of Smeared Cracking Model, Chongqing University, Chongqing, China, 2013.

[23] B. Schütte and V. Sigrist, "Shear assessment of compression flanges of structural concrete T-beams," Frontiers of Structural and Civil Engineering, vol. 8, no. 4, pp. 354-361, 2014.

[24] J. Han and Y. He, "Experimental study on effective tensile concrete section area," Water Conservancy and Hydropower Engineering, vol. 31, no. 5, pp. 120-121, 2009.

[25] R. H. Scott and P. A. T. Gill, "Short-term distributions of strain and bond stress along tension reinforcement," The Structural Engineer, vol. 24, no. 2, pp. 39-43, 1987. 
[26] Bo $\mathrm{Yu}, \mathrm{S}$. Li, and $\mathrm{X}$. Yan, "Effective restrained radius of confined concrete," Journal of Tsinghua University (Science and Technology), vol. 45, no. 3, pp. 289-292, 2005.

[27] J. Vu, M. G. Stewart, and J. Mullard, "Corrosion-induced cracking: experimental data and predictive models," Structural Journal, vol. 102, no. 5, pp. 719-726, 2005.

[28] Z. Wang, Y. Tian, N. Jin, X. Jin, and H. Jiang, "Measurement of strain field in corroded reinforced concrete with DVC method," Concrete, vol. 12, no. 350, pp. 11-17, 2018.

[29] X. Du, R. Zhang, and L. Jin, "Meso-scale numerical investigation on the crack process of concrete cover induced by rebar non-uniform corrosion," Journal of Civil, Architectural \& Environmental Engineering, vol. 37, no. 1, pp. 73-80, 2015.

[30] J. Liu, R. Zhang, X. Du, and Y. Li, "Investigation on cracking behavior of concrete cover induced by corner located rebar corrosion," Journal of Building Materials, vol. 19, no. 2, pp. 255-261, 2016.

[31] B. Wang, H. Wang, Z. Zhang, and M. Zhou, "Analysis of corrosion-expansion-induced cracks on concrete cover based on XFEM," Journal of Hohai University, vol. 45, no. 2, pp. 161-166, 2017.

[32] J. Tong, X. Jin, Y. Tian, and N. G. Jin, "Study on surface cracking of corroded reinforced concrete based on DIC method," Journal of Zhejiang University, vol. 49, no. 2, pp. 193-217, 2015.

[33] Y. Zhao and W. Jin, "Numerical-based method for calculating reinforcement corrosion at concrete cover cracking due to corrosion," Journal of Zhejiang University (Engineering Science), vol. 6, no. 42, pp. 1080-1084, 2008.

[34] J. Qiu, Li Yan, X. Mao, S. Wang, and T. Ma, "Numerical simulation of concrete cover cracking induced by rebar nonuniform corrosion in offshore environment," Concrete, vol. 7, no. 345 , pp. $8-15,2018$.

[35] X. Du, L. Jin, and R. Zhang, "Modeling the cracking of cover concrete due to non-uniform corrosion of reinforcement," Corrosion Science, vol. 89, no. 7, pp. 189-202, 2014.

[36] X. Zhang, J. Wang, and Y. Zhou, "Analytical modeling for corrosion-induced cover cracking of corrosive reinforced concrete structures," Transactions of Tianjin University, vol. 18, no. 4, pp. 285-290, 2012. 